\title{
How to Remove Dirty Money Effect?
}

\author{
Xinyue Hu*, Jun Ren, Xiu Mei and Chen Zeng \\ Zhejiang Normal University, China \\ *Corresponding author: Xinyue Hu, Department of Psychology, Zhejiang Normal University, Jinhua 321004, China
}

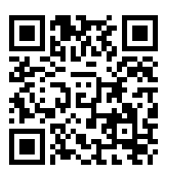

\section{ARTICLE INFO}

Received: 㓞 March 11, 2019

Published: 蔧 March 18, 2019

\section{ABSTRACT}

Citation: Xinyue Hu, Jun Ren, Xiu Mei, Chen Zeng. How to Remove Dirty Money Effect?. Biomed J Sci \& Tech Res 16(1)-2019. BJSTR. MS.ID.002795.

\section{Introduction}

DME is caused by the exposure to filth money instead of clean and pure money and it shows that dirty money can lead to unfair behavior. DME was first discovered by Qing Yang et al. [1] through one field study and other six laboratory studies. Qing Yang et al. [1] proposed that people may have two different views on money. They found that dirty money and clean money show differences in attitude, value and interpersonal behavior. But how can we remove DME so that people can get fair treatment? We use trust game paradigm to test the fairness.

\section{Method}

\section{Participants}

172 undergraduates (162 female, 10 male, Mage=22) in Zhejiang Normal University participated in exchange for Renminbi (Chinese money). They were randomly assigned to one of four conditions in a $2 \times 2$ between-subjects design (clean vs. dirty; pretended wiping vs. no wiping).

\section{Material}

Clean money, dirty money, PANAS (positive and negative emotion scale), trust game paradigm on computers (screen resolution=1024x768).The trust game [2] has been used to examine people's willingness to trust others and their willingness to live up to others' trust in them.Preparation of the money: Take out from the bank 200 pieces new and clean money with a face value of 10 yuan ( $¥ 10$ ), a total of $¥ 2000$. One hundred of them ( $¥ 1000$ ) are put into a white plastic bag filled with mud [1]. After 3-4 days, check if the 100 pieces of money has been dirty, if not: put them into the plastic bag again until they are dirty.

\section{Procedure}

Participants entered the experiment one at a time and signed the consent form. Firstly, participants were asked to finish the PANAS (positive and negative emotion scale). Then, participants were asked to write the things they did in the past 24 hours, in the same time, in wipe group: our experimenter took out the money from the box and pretend to wipe the money; in non-wipe group: experimenter just took out the money from the box. Three minutes later the paper written by the participants would be taken by the experimenter. Next, the participants were told to finish a finger dexterity measure task. They were asked to count out 20 pieces dirty or clean $¥ 10$ bills 5 times. The dirty money had been put in the bag of dirty for several days before. Then, participants were asked to finish the PANAS again. Fifthly, they played a simplified trust game on a computer. The instructions were displayed: there are two characters in this game, the distributor and the receiver. In the experiment, distributor will be given some money, he has the right to decide how much to give to the receiver, and the receiver will receive money which was three times of the amount distributor decided (processed by the experimenter).

Then the receiver can decide how much money return to the distributor. The instruction would say: You will complete the experiment with another person randomly selected by the computer. If you understand the guide, press the " $\mathrm{A}$ " button to begin the experiment. After the participant pressed, the instruction would say: congratulations! You were chosen randomly as the receiver. Please press " $\mathrm{B}$ " to continue. Then the instruction showed: the distributor decides to give you all $¥ 10$, now the money you have 
is $¥ 30$. How much do you decide to return to the distributor? Please press the answer button. Each participant only played one round. The amount of money returned would be recorded by the computer. Finally, the participants did the operation test to check the validity.

\section{Results}

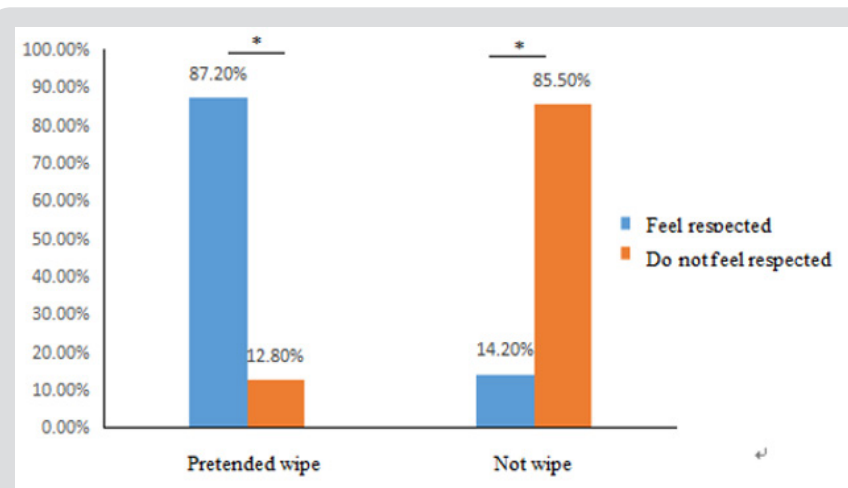

Note: $\mathrm{p}<.05$

Figure 1: Feel respected or not in different condition.

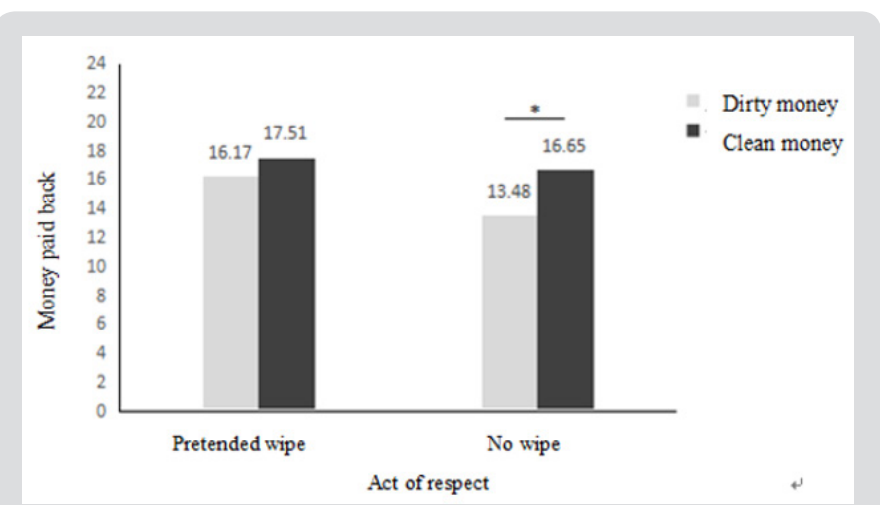

Note: ${ }^{*} \mathrm{p}<.05$

Figure 2: Amount of money that participants would pay back in pretended wipe condition and no wipe condition.

There are 140 (84\%) participants noticed the action of wiping the money while $26(16 \%)$ participants did not notice the wiping action. We conducted Chi-square test to test whether the wiping action can represent respect. The results indicated a significant difference in feeling respected or not between pretended wipe and no wipe, $\mathrm{p}<.05$, and the probability of feeling respected are significantly higher when pretended wipe, see Figure 1. We assume that the respectful act can eliminate the DME. The predictions were tested with a $2 \times 2$ analysis of variance (ANOVA). Clean group $(\mathrm{M}=17.09, \mathrm{SD}=3.83)$ gave significantly much more money than dirty group ( $M=14.83, S D=3.63), p<.05, \eta 2=.091$. Pretended wiping group $(M=16.84, S D=3.97)$ gave significantly much more money back than no wipe group ( $M=15.01, S D=3.62), p<.05, \eta 2=.058$. But the interaction is not significant $(p>.05)$. Further using the pairwise comparison results, we find that: in the no wiping condition, clean money group $(M=16.65, S D=3.57)$ gave back significantly much more money than dirty money group $(\mathrm{M}=13.48, \mathrm{SD}=2.95)$; in the pretended wiping condition, clean money group $(M=17.51, S D=4.09)$ and dirty money group $(M=16.17, S D=3.78)$ did not have significant difference in the amount of money paid back; in the condition of dirty money, the pretended wipe group $(M=16.17, S D=3.78)$ paid significantly much more money than no wipe group $(M=13.48, S D=2.95)$ see Figure 2. Measure positive and negative emotions before and after One-way ANOVA was used to test with the emotions data as the dependent measure. It turns out that there is no significant difference between the before and after positive and negative emotion data.

\section{Discussion}

We found that DME on moral responses during an economic decision game were moderated by whether wiping. And whether there are respectful actions can significantly affect the amount of money returned by the participant. In addition, neither contact with dirty money nor clean money can cause changes in the emotions of the participants. It shows that respectful action can eliminate the unfair effects of dirty money. In addition, although the action of pretending to wipe can indicate respect for the subjects, it can be seen from the experimental results that not all the participants thought that the action of pretending to wipe made them feel respected, this may be due to the personality characteristics of the participants themselves, which makes them feel that this action does not represent anything.

\section{References}

1. Yang Q Wu X, Zhou X, Mead NL, Vohs KD, et al. (2013) Diverging effects of clean versus dirty money on attitudes, values and interpersonal behavior. J Pers Soc Psychol 104(3): 473-489.

2. Burks SV, Carpenter JP, Verhoogen E (2003) Playing both roles in the trust game J Economic Behavior Organization 51(2): 195-216.

\section{ISSN: 2574-1241}

DOI: 10.26717/BJSTR.2019.16.002795

Xinyue Hu. Biomed J Sci \& Tech Res

This work is licensed under Creative

Commons Attribution 4.0 License

Submission Link: https://biomedres.us/submit-manuscript.php

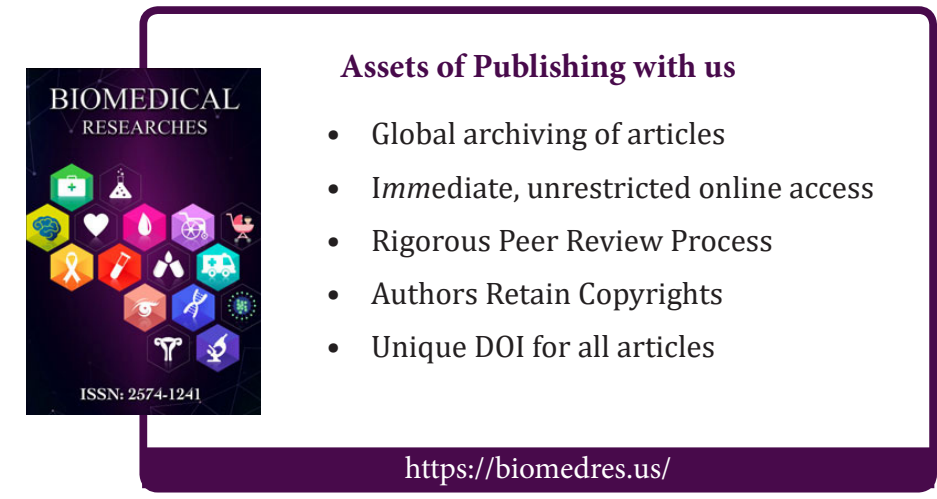

